\title{
OPTIMIZATION OF THE INTEGRATION PROCESS IN THE SPHERE OF PROGRAM-TARGET MANAGEMENT OF SOCIO-ECONOMIC DEVELOPMENT OF THE REGIONS OF RF
}

\section{Abstract}

The article presents the results of the study of the feasibility of inter-regional integration. According to the results of the study, the leading indicators of the integration potential of regional targeted development programs were identified. The matrix model for the optimization of the integration process, which takes into account the unevenness of obtaining promising results of targeted regional development, is presented. It is proved that the partnership of the regions in the target development of territories is more preferable than the implementation of local strategies.

Keywords: region, innovation, integration, potential, management, resources, criteria, optimization, program goals management.

\section{References}

1. Ignatova T.V., Mikryukova M.YU., Mnacakanova E.R. Institucional'noe oformlenie praktik importozameshcheniya v kontekste ekologicheskogo menedzhmenta territorii // Vestnik Evrazijskoj nauki. 2019. № 1. http:// https://esj.today/PDF/34ECVN119.pdf (Dostup svobodnyj). Zagl. s ekrana. YAz. rus., angl.

2. Ryabova T.F. Innovacionnoe razvitie - bazis konkurentnyh preimushchestv ekonomiki organizacij APK // Mezhdunarodnye nauchnye issledovaniya. 2017. № 2 (31). P. 232 - 236.

3. Minaeva E.V., Ryabova T.F., Deeva V.A. Metodologiya issledovaniya slozhnyh sistem // Rossijskoe predprinimatel'stvo. 2008. № 2. P. 86 - 90.

4. Orlovskij S.A. Problemy prinyatiya reshenij pri nechetkoj iskhodnoj informacii. - M.: Nauka, 1981. $208 \mathrm{~s}$.

5. Borisov A.N., Alekseev A.V., Merkur'eva G.V. Obrabotka nechetkoj informacii v sistemah prinyatiya reshenij. - M.: Radio i svyaz', 1989. 304 s.

6. Kendel M. Rangovye korrelyacii. - M.: «Statistika», 1975. 216 s.

7. Pavlov S.N. Avtomatizirovannye delovye igry sistem upravleniya. - M.: MING, 1990. 36 s.

\section{СОДЕРЖАНИЕ ПОНЯТИЯ «УСЛУГА» ПРИМЕНИТЕЛЬНО К МЕЖДУНАРОДНЫМ ТОРГОВО-ЭКОНОМИЧЕСКИМ ОТНОШЕНИЯМ}

\section{Еликбаев Куаныш Нурланович}

(117198, Россия, г. Москва, ул. Миклухо-Маклая, 6). E-mail: kuan1@mail.ru

\section{Аннотация}

Понятие «услуга» глубоко проработанное в экономической теории, имеет неоднозначное содержание при ее использовании для целей международной торговли. Однозначный терминологический аппарат становится условием повышения эффективности межгосударственного торгово-экономического сотрудничества. В условиях формирования единого рынка услуг в рамках различных интеграционных объединений точное определение термина «услуги» приобретает особую значимость. В статье сделана попытка уточнения содержания понятия «услуга», используемого для целей международного торговоэкономического сотрудничества государств.

Ключевые слова: услуга, понятие, международная торговля услугами, единый рынок услуг, торговоэкономические отношения, мировая экономика, экспорт, импорт, темпы роста экспорта услуг.

Характерной чертой последних десятилетий развития мировой экономики является повышение роли сектора услуг. О динамичном развитии данного сектора свидетельствуют статистические данные международных организаций (табл. 1).

Начиная с 2000-х гг., можно отметить динамичный рост импорта и экспорта услуг между государствами мира: среднегодовые темпы роста экспорта услуг в 2000 - 2008 гг. составили 11,3 \%, значение аналогичного показателя по импорту услуг составило 11,1 \%. Падение импорта и экспорта услуг в 2009 г., обусловленное кризисом мировой экономики, сменилось ростом: с 2010 по 2014 гг. среднегодовые темпы прироста экспорта услуг составляли 7,5 \%, среднегодовые темпы прироста импорта услуг составили 7,7 \%. В 2015 г. произошел незначительный спад импорта и экспорта услуг, который сменился ростом в 2016 - 2017 гг. Вместе с динамичным развитием, международная торговля услугами оказалась более устойчивой к кризисным явлениям: если падение мирового экспорта услуг в 2009 г. составило порядка 13 \%, то падение экспорта товаров превысило 23 \%.

Экспорт и импорт услуг, по данным на 2017 год, в текущих ценах превысил 5 трлн. долл., что выше аналогичных показателей в 2000 г. на 221,2 \% и 211,1 \%, соответственно. Таким образом, экспорт и импорт услуг в 2017 г. вырос более чем в 3 раза в сравнении с 2000 г. Крупными секторами международной торговли становятся банковские услуги, страхование, транспортные услуги, логистические услуги, информационно-коммуникационные услуги, инжиниринговые услуги и др. Добавленная стоимость сферы услуг в совокупном ВВП стран мира по данным на 2017 год составила 65 \%. При этом в ряде стран этот показатель превышает 65 \%. 
Темпы прироста/убыли мирового экспорта и импорта услуг в мире, 2000 - 2017 гг. $^{1}$

\begin{tabular}{|c|c|c|c|c|c|c|}
\hline \multirow[b]{3}{*}{ Годы } & \multirow{2}{*}{\multicolumn{2}{|c|}{$\begin{array}{c}\text { Абсолютные значения, } \\
\text { трлн. долл. }\end{array}$}} & \multicolumn{4}{|c|}{ Динамические значения } \\
\hline & & & \multicolumn{2}{|c|}{ Экспорт услуг } & \multicolumn{2}{|c|}{ Импорт услуг } \\
\hline & 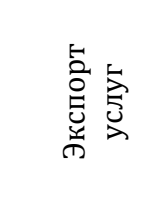 & 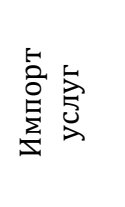 & 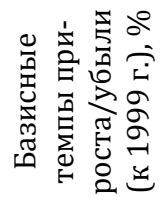 & 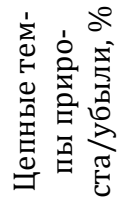 & 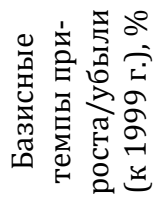 & 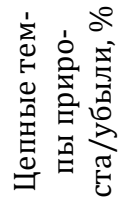 \\
\hline 2000 г. & 1,686 & 1,640 & 6,8 & 6,8 & 7,1 & 7,1 \\
\hline 2001 г. & 1,686 & 1,650 & 6,8 & 0,0 & 7,7 & 0,6 \\
\hline 2002 г. & 1,805 & 1,734 & 14,3 & 7,0 & 13,2 & 5,1 \\
\hline 2003 г. & 1,995 & 1,965 & 26,4 & 10,6 & 28,3 & 13,3 \\
\hline 2004 г. & 2,429 & 2,362 & 53,8 & 21,7 & 54,2 & 20,2 \\
\hline 2005 г. & 2,693 & 2,611 & 70,5 & 10,9 & 70,5 & 10,5 \\
\hline 2006 г. & 3,033 & 2,916 & 92,1 & 12,6 & 90,4 & 11,7 \\
\hline 2007 г. & 3,625 & 3,433 & 129,5 & 19,5 & 124,1 & 17,7 \\
\hline 2008 г. & 4,074 & 3,891 & 158,0 & 12,4 & 154,0 & 13,3 \\
\hline 2009 г. & 3,637 & 3,464 & 130,3 & $-10,7$ & 126,2 & $-11,0$ \\
\hline 2010 г. & 3,921 & 3,739 & 148,3 & 7,8 & 144,1 & 7,9 \\
\hline 2011 г. & 4,475 & 4,230 & 183,4 & 14,1 & 176,2 & 13,1 \\
\hline 2012 г. & 4,602 & 4,379 & 191,4 & 2,8 & 185,9 & 3,5 \\
\hline 2013 г. & 4,896 & 4,649 & 210,1 & 6,4 & 203,5 & 6,2 \\
\hline 2014 г. & 5,211 & 5,015 & 230,0 & 6,4 & 227,4 & 7,9 \\
\hline 2015 г. & 4,993 & 4,766 & 216,2 & $-4,2$ & 211,1 & $-5,0$ \\
\hline 2016 г. & 5,045 & 4,775 & 219,5 & 1,0 & 211,7 & 0,2 \\
\hline 2017 г. & 5,416 & 5,104 & 243,0 & 7,4 & 233,2 & 6,9 \\
\hline
\end{tabular}

В последние годы растет и занятость в сфере услуг. По данным на 2018 г. она превысила 51,7 \%², при этом в более чем в 120 странах мира доля занятых в сфере услуг выше медианного значения данного показателя по всем государствам.

Рост значимости сектора услуг в мировой экономике закономерно повысил интерес исследователей к теоретическим вопросам развития международной торговли услугами. Можно, к примеру, выделить исследования О.В. Бирюковой [1-2], Р.В. Железнова [3], Г.В. Кузнецовой [4], Н.С. Милоголова [6], Ю.В. Пискулова [7] и многих других. В существующих исследованиях основной внимание уделяется механизмам организации международной торговли услугами, регулированию рынка услуг, прочим аспектам функционирования международного рынка услуг и в незначительной мере рассматривается содержание понятия «услуги» в контексте формирования международных торгово-экономических отношений.

Содержание понятия «услуга» глубокого проработано в многочисленных работах ученых, которые рассматривали ее преимущественно на уровне процесса оказания услуги «субъект предоставления услуги-получатель услуги». На международном уровне процесс оказания услуги не меняет своего содержания, но обретает специфику, которая определяется трансграничным характером данной экономической деятельности, что требует некоторых теоретических уточнений.

Все многообразие подходов к определению понятия «услуга» можно условно разделить на классификационные группы:

- группа научных подходов, где данное понятие уточняется и используется сугубо в теоретических целях;

- официальная трактовка понятия «услуга», используемая в деятельности органов государственной власти на национальном уровне, а также в международных правовых актах;

- подходы к определению понятия «услуга», используемые в деятельности международных организаций, не являющиеся общеобязательными и используемые осуществления функций таких организаций (например, в статистических целях, при определении различных видов услуг и их трансграничного движения (информационно-коммуникационных, транспортных, финансовых и др.).

\footnotetext{
${ }^{1}$ World Bank Open Data [Электронный ресурс] / Всемирный Банк. URL - https://data.worldbank.org (дата обращения 03.07.2019 г.)

2 Там же.
} 
На теоретическом уровне первые научные исследования о сущности «услуги» появились уже в XIX в. в работах Ж.-Б. Сея [8], А. Смита [9], А. Маршалла [5]. Названные зарубежные исследователи одними из первых выделили актуальные и по сей день свойства услуг, которые позволяют выделить их в ряду прочих результатов экономической деятельности:

- особый характер экономического обмена при предоставлении услуг в отличии от движения материальной продукции;

- неосязаемость услуг;

- услуги не могут храниться;

- услуги не фиксируются в каком-либо ощутимом продукте;

- услуга есть деятельность и др.

Понятие «услуга» широко используется и уточняется в работах исследователей, развивавших маркетинговую методологию. Данное понятие могли определять как согласованное взаимодействие нескольких субъектов рыночных отношений, реализуемое с целью создания, расширения или воспроизводства возможностей таких субъектов в получении благ (пользы) [11]. Под услугой также понимается «полезное действие», заключенное в потребительной стоимости товара или труда..

Все многообразие способов определения понятия «услуга» авторы предлагают систематизировать, объединив их в группы: 1) подходы, в которых услуга рассматривается как деятельность: процесс; действие; вид деятельности, деятельность; мероприятие; отношения между людьми; хозяйственная деятельность; взаимодействие; 2) подходы, где услуга рассматривается как цель деятельности: выгода; блага; результат деятельности; результат взаимодействия; продукт труда; товар; содействие удовлетворению потребностей; удовлетворение потребностей [10; 12$]$.

На основе изучения подходов к определению понятия «услуга», можно выделить основные свойства услуг:

- свойства, отличающие услугу от материальной продукции и от работ: неосязаемость, несохраняемость, невозможность стандартизации и массовизации, неотделимость от источника, оказывающего услуги;

- участники экономических отношений, связанных с оказанием и потреблением услуг: а) субъекты экономических отношений, предоставляющие услуги (организации, физические лица); б) покупатели (потребители) услуг, которые также могут выступать индивидуальными и коллективными субъектами экономических отношений;

- оказание услуг есть процесс, целью которого становится получение результата в форме блага, пользы, выгод её получателю.

Сложнее проблема понятия «услуга» разрешается на международном уровне при уточнении государствами-участниками границ этого понятия, используемого, к примеру, для целей создания единых рынков услуг. Например, в Генеральном соглашении по торговле услугами (ГАТС) это понятие не определяется, но в ст. 1 отмечается, что «услуги» включают любую услугу в любом секторе, кроме услуг, поставляемых при осуществлении функций правительственной власти ${ }^{1}$. В ГАТС торговля услугами определяется как поставка услуг четырьмя способами: трансграничная поставка; потребление за рубежом; коммерческое присутствие; присутствие физических лиц, предоставляющих услугу.

Некоторый вклад в понимание термина «услуги» на уровне международных торговых отношений вносят существующие классификаторы услуг. Потребность в таких классификаторах возникла в связи с усложнением объемов международной торговли услугами, необходимостью их регулирования на многостороннем уровне. Так, во время Уругвайского раунда ВТО принят классификатор услуг, основанный на базе Временного классификатора основного продукта ОOH.

Таким образом, создан Классификатор услуг ГАТС, используемый в ВТО в ходе переговоров по либерализации торговли услугами и подготовки обязательств государств-членов соглашения. Классификатор содержит более 180 позиций, сгруппированных в 12 разделов.

Понятие «услуга» не определяется и в других региональных соглашениях. Например, в Договоре о Евразийском экономическом союзе используется понятие «единый рынок услуг» понимается состояние рынка услуг в конкретном секторе, в котором каждое государство-член предоставляет лицам любого другого государства ряд преференциальных прав².

Подводя итог данному исследованию, отметим, что на международном уровне непосредственно понятие «услуга» не претерпевает существенных изменений, но трансформируется содер-

\footnotetext{
1 General Agreement on Trade in Services [Электронный ресурс] / World Trade Organization. URL https://www.wto.org/ENGLISH/tratop_e/serv_e/gatsintr_e.htm (дата обращения 14.01.2019 г.)

2 Договор о Евразийском экономическом союзе [Электронный ресурс] / Консультант. URL http://www.consultant.ru/document/cons_doc_LAW_163855/ (дата обращения 02.07.2019 г.)
} 
жание процесса, предшествующего и, в отдельных случаях, сопутствующего их оказанию, а также сущности международных транзакций, обусловленных торговлей услугами на межгосударственном уровне. Содержание понятия «услуга» на международном уровне расширяется способами организации их трансграничного движения. В международной практике сложилось четыре способа организации международной торговли услуг: трансграничная поставка, потребление за рубежом, коммерческой присутствие, присутствие физических лиц, предоставляющих услуги. Такое понимание услуг не означает, что услуги не рассматриваются как процесс или как деятельность. На международном уровне меняется содержание субъектов оказываемых услуг, экономическое содержание процесса оказания услуги и организации торговли услугами.

\section{Литература}

1. Бирюкова О.В. Торговля услугами как локомотив интеграции // Азия и Африка сегодня. 2014 . № 5 (682). C. 35-40.

2. Бирюкова O.B. Торгово-политический инструментарий в международной торговле услугами: монография. - М.: Экономика, 2013. 286 с.

3. Железнов Р.В. Принцип либерализации международной торговли услугами в международном торговом праве: автореф. дис. ... канд. юрид. наук: 12.00.10 / Железнов Родион Викторович. - Казань, 2017. 24 с.

4. Кузнецова Г.В. Современное положение России на мировом рынке услуг // Вестник Российского государственного торгово-экономического университета (РГТЭУ). 2014.№ 12 (91). С. 18 - 29.

5. Маршалл А. Принципы экономической науки. - М.: Директ-медиа, 2012. 2127 с.

6. Милоголов Н.С. Налог на добавленную стоимость по операциям международной торговли услугами: автореф. дис. ... канд. экон. наук. М., 2014. 25 с.

7. Пискулов Ю.В. Международная торговля товарами и услугами. Россия в ВТО. - М.: ВАВТ, 2013.103 с.

8. Сей Ж.-Б. Трактат по политической экономии. - М.: Дело, 2000. 232 с.

9. Смит А. Исследование о природе и причинах богатства народов / Директмедиа Паблишинг. М., 2008. 655 с. 10.Степанова B.C. О теоретических подходах к содержанию понятия "услуга" // Сборники конференций НИЦ Социосфера. 2014. № 43. С. $104-115$.

11. Челенков А.П. Маркетинг услуг: продукт // Маркетинг. 1998. № 1. С. 116 - 120.

12. Cowell, D. The Marketing of Services / D. Cowell. - London : Heinemann, 1984.

Elikbayev Kuanysh Nurlanovich, graduate student, Peoples' Friendship University of Russia (6, Miklukho-Maclay St., Moscow, 117198, Russian Federation). E-mail: kuan1@mail.ru

\section{THE MAINTENANCE OF THE CONCEPT "SERVICE" IN RELATION TO THE INTERNATIONAL TRADE} AND ECONOMIC RELATIONS

\section{Abstract}

The concept "service" which is deeply worked in the economic theory has ambiguous contents at its use for international trade. The unambiguous terms framework becomes a condition of increase in efficiency of interstate trade and economic cooperation. In the conditions of formation of the uniform market of services within various integration associations exact definition of the term "services" gains the special importance. In article the attempt of specification of maintenance of the concept "service" used for the international trade and economic state cooperation is made.

Keywords: service, concept, international trade in services, uniform market of services, trade and economic relations, world economy, export, import, growth rates of export of services.

\section{References}

1. Biryukova O.V. Torgovlya uslugami kak lokomotiv integracii // Aziya i Afrika segodnya. 2014. № 5 (682). P. 35-40.

2. Biryukova O.V. Torgovo-politicheskij instrumentarij $\mathrm{v}$ mezhdunarodnoj torgovle uslugami: monografiya. - M.: Ekonomika, 2013. 286 s.

3. ZHeleznov R.V. Princip liberalizacii mezhdunarodnoj torgovli uslugami v mezhdunarodnom torgovom prave: avtoref. dis. ... kand. yurid. nauk: 12.00 .10 / ZHeleznov Rodion Viktorovich. - Kazan', 2017. 24 s.

4. Kuznecova G.V. Sovremennoe polozhenie Rossii na mirovom rynke uslug // Vestnik Rossijskogo gosudarstvennogo torgovo-ekonomicheskogo universiteta (RGTEU). 2014.№ 12 (91). P. 18 - 29.

5. Marshall A. Principy ekonomicheskoj nauki. - M.: Direkt-media, 2012. 2127 s.

6. Milogolov N.S. Nalog na dobavlennuyu stoimost' po operaciyam mezhdunarodnoj torgovli uslugami: avtoref. dis. ... kand. ekon. nauk. M., 2014. 25 s.

7. Piskulov YU.V. Mezhdunarodnaya torgovlya tovarami i uslugami. Rossiya v VTO. - M.: VAVT, 2013.103 s.

8. Sej ZH.-B. Traktat po politicheskoj ekonomii. - M.: Delo, 2000. $232 \mathrm{s.}$

9. Smit A. Issledovanie o prirode i prichinah bogatstva narodov / Direktmedia Pablishing. M., 2008. $655 \mathrm{~s}$.

10. Stepanova V.S. O teoreticheskih podhodah k soderzhaniyu ponyatiya "usluga" // Sborniki konferencij NIC Sociosfera. 2014. № 43. P. 104 - 115.

11. CHelenkov A.P. Marketing uslug: produkt // Marketing. 1998. № 1. P. 116 - 120.

12. Cowell, D. The Marketing of Services / D. Cowell. - London: Heinemann, 1984. 